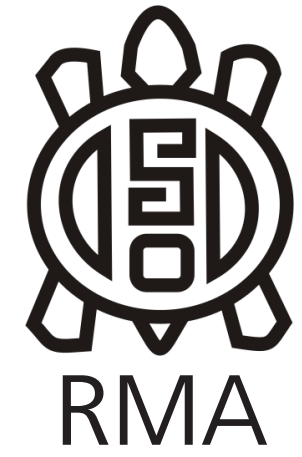

Antropología Social

\title{
"No teníamos idea cómo era ir a un ministerio a abrir gestiones" Apropiación de saberes cotidianos de la militancia territorial en una organización social de la ciudad de Córdoba (Argentina)
}

\author{
"We had no idea how to initiate an administrative process in a ministry" \\ Appropriation of everyday knowledge of territorial militancy in a social \\ organization from Córdoba (Argentina)
}

Lucía Caisso*

*Centro de Investigaciones y Transferencia/ CONICET - UNRaf. E-mail: lucia.caisso@gmail.com

\begin{abstract}
Resumen
Este artículo presenta un análisis de la dimensión educativa de las prácticas de militancia territorial en una organización social de la ciudad de Córdoba. Se trata de una indagación que se inscribe en una investigación antropológica más amplia sobre experiencias educativas en movimientos sociales. Desde un enfoque teórico-metodológico relacional se reconstruyen saberes cotidianos que los sujetos se apropian a propósito de su militancia territorial. Se analizan para ello relatos de vida obtenidos a partir de entrevistas en profundidad y rutinas militantes reconstruidas a partir de observaciones participantes. Esta exploración permite evidenciar cómo lo sujetos se apropian de destrezas y formas de saber-hacer que son requeridos para la militancia territorial en función de contextos sociales y políticos concretos y en interacción con agentes, políticas y actuaciones estatales. Las transformaciones, crisis y reconversiones que se operan sobre esos saberes ponen de manifiesto la interpenetración existente entre la vida cotidiana de los sujetos y los contextos sociales más amplios que la configuran.
\end{abstract}

Palabras clave: Antropología; Educación; Política; Enfoque relacional

\begin{abstract}
This article presents an analysis of the educational dimension of the practices inherent to the territorial militancy of a social organization based in the city of Córdoba. It is an inquiry that inscribes in broader anthropological research about the educational experiences reaped within social movements. Taking a relational methodological and theoretical approach, we reconstruct the daily knowledge subjects gain when involved in territorial militancy. To this end, we analyze both life stories obtained from in-depth interviews and militant routines reconstructed from participant observations. This exploration allows us to show how subjects incorporate the skills and the forms of know-how required in territorial militancy according to specific social and political contexts and in interaction with state agents, policies, and actions. The transformations, crises, and reconversions that act upon this knowledge reveal the interpenetration that occurs between the daily life of the subjects and the broader social contexts that shape it.
\end{abstract}

Keywords: Anthropology; Education; Politics; Relational approach

\section{Introducción}

En la investigación que inicié en el año 2009 en el marco de mis estudios de posgrado en Ciencias de la Educación indagué en las experiencias educativas desarrolladas por una organización social de la ciudad de Córdoba', Argentina. Esta organización -a la que aludiré

\footnotetext{
1 La ciudad de Córdoba es capital de la provincia homónima, ubicada en el centro geográfico de la República Argentina. Es la segunda ciudad más poblada de Argentina (1.329.000 habitantes) y posee una rica herencia colonial vinculada a diferentes órdenes religiosas de la Iglesia Católica. Su universidad fue la primera y una de las más importantes
}

como el Movimiento²- estaba desarrollando la primera de América Latina. A lo largo del siglo XX fue escenario de numerosas revueltas políticas que tuvieron como protagonistas a los estudiantes universitarios, a los obreros fabriles (fundamentalmente de la industria metal-mecánica y automotriz) y más de una vez a la confluencia entre ambos sectores. En la actualidad Córdoba continúa siendo un escenario de eventos políticos tan contradictorios como relevantes en el escenario político nacional.

2 A lo largo de este texto omito o sustituyo por seudónimos los nombres reales de la organización social que llevaba adelante las experiencias educativas analizadas y lo de todas las personas entrevistadas o cuyas prácticas y rutinas cotidianas fueron observadas en el transcurso del trabajo de campo. 
experiencia de Bachillerato Popular del interior del país 3 . Ese Bachillerato se constituyó, en aquel entonces, en la unidad de análisis de mi investigación.

Sin embargo, un tiempo después de iniciado el trabajo de campo, los integrantes del Movimiento decidieron iniciar también un espacio educativo de nivel primario para adultos, enmarcado dentro del programa estatal FinEs Primaria. La normativa oficial de este plan contemplaba que el mismo pudiera ser implementado en organizaciones de ya que la normativa oficial del mismo contemplaba que pudiera ser implementado en organizaciones de la sociedad civil que contaran con -al menos- un adulto con título de maestro de grado. Una vez que este espacio educativo enmarcado de nivel primario comenzó a ser desarrollado con regularidad en uno de los locales ${ }^{4}$ del Movimiento, decidí abordarlo también -junto con el Bachillerato- como referente empírico de mi investigación.

La apertura consecutiva de ambos proyectos educativos en el seno del Movimiento y a mediados de la década de 2000 no era casual, sino que expresaba un fenómeno más generalizado -cuyas causas abordaré más adelante- por el cual numerosas organizaciones y movimientos sociales venían abocándose al desarrollo de actividades educativas en los barrios donde desplegaban su trabajo político. A la par del crecimiento de estas actividades se mantenía no obstante el desarrollo de otras actividades que, en el caso del Movimiento, eran nombradas como actividades territoriales o del sector territorial.

Si bien en un principio me costó advertir en qué sentido las actividades educativas no eran territoriales -o viceversacon el tiempo fui entendiendo las particularidades que distinguían a cada conjunto. Aunque los dos tipos de actividades se desarrollaban en barrios aledaños de la zona sud-este de la ciudad, las clases del Bachillerato Popular y del Fines Primaria atraían mayormente -en tanto estudiantes- a personas que vivían en los barrios de calles pavimentadas y casas de material, con trabajos formales y un recorrido de varios años por el sistema educativo. No eran tampoco, en general, personas que hubieran participado previamente de actividades del Movimiento. Al mismo tiempo, estas actividades convocaban a jóvenes activistas con estudios de nivel superior en curso

3 Los Bachilleratos Populares -escuelas secundarias para jóvenes y adultos con perspectiva de "educación popular"- comenzaron a surgir a mediados de la década de 2000 en Argentina, impulsados por diferentes organizaciones políticas y sociales y, fundamentalmente, por aquellas vinculadas con las corrientes ideológicas autonomistas. Han llegado a cerca de 90 Bachilleratos Populares a lo largo del país en el año 2015. Una vez que estos son abiertos buscan obtener su "oficialización": es decir, conseguir que el Ministerio de Educación de la jurisdicción a la que pertenece ese Bachillerato los reconozca como escuelas "de gestión social" (figurada reconocida por la Ley de Educación Nacional sancionada en 2006) y por ende se les conceda la posibilidad de otorgar certificaciones educativas a sus estudiantes. 4 "Local" es un término que se utiliza en Argentina para aludir a las casas, galpones o espacios cerrados que poseen o alquilan las organizaciones políticas y movimientos sociales para desarrollar sus actividades. o concluidos, que se sumaban para participar como educadores en ellas aunque no tenían un vínculo político orgánico con el Movimiento o pertenecían, inclusive, a otras organizaciones sociales.

Por su parte, las actividades territoriales que se seguían manteniendo al interior del Movimiento, tenían como destinatario principal a los pobladores de los asentamientos irregulares o villas de emergencia de la zona sud-este. Eran actividades orientadas a organizar a los pobladores de esos lugares en torno a la obtención de planes de trabajo cooperativo (en comedores populares, fabricación de ladrillos o emprendimientos textiles), a demandar bolsones de alimentos ${ }^{5}$, útiles escolares para niños y niñas o reclamar mejoras en la infraestructura y los servicios públicos de la zona (que eran, en general, defectuosos). Pude distinguir que no se trataba de actividades en las que se involucraban todos los integrantes del Movimiento que yo había conocido a través de mi trabajo de campo en el Bachillerato Popular y el Plan FinEs. Por el contrario, de ellas se encargaban centralmente Gastón y Eugenia, la pareja que había fundado el Movimiento y que tenía mayor antigüedad en la organización.

El registro de las particularidades existentes en lo que parecían ser dos sectores diferenciados al interior del Movimiento me resultaron productivas porque me permitieron, en primer lugar, explicar algunas de las tensiones que atravesaban la cotidianeidad del Bachillerato Popular y el espacio FinEs. Pero al mismo tiempo, ese registro me fue acercando cada vez más al universo de las actividades territoriales: comencé a preguntarme si a propósito de ellas no se producía también -aunque de manera más informal, asistemática e implícita- una actividad educativa. Persiguiendo esta inquietud comencé a acompañar y a observar a Eugenia y Gastón en sus rutinas militantes vinculadas a las actividades territoriales y decidí analizar de qué saberes cotidianos ellos se apropiaban a propósito de las mismas.

La perspectiva teórico-metodológica que adopté a lo largo de mi investigación (para abordar tanto las experiencias del Bachillerato Popular y el espacio FinEs como los saberes cotidianos de la militancia territorial) estuvo orientada por el enfoque relacional en Antropología, el cual concibe al mundo social como dialéctico, contradictorio, complejo y en constante transformación (Achilli, 2005). La principal premisa teórico-metodológica de este enfoque es, según Menéndez (2002, 2010), que las relaciones que se dan entre los diferentes actores sociales constituyen una realidad diferente de la obtenida a partir de la descripción y análisis de cada uno de los actores en términos particulares y aislados. A su vez, esas

5 Con el término "bolsón" se alude a una partida de alimentos no perecederos otorgados por el estado en cualquiera de sus niveles: municipal, provincial o nacional. Estas partidas de alimentos suelen ser solicitadas, receptadas y repartidas por distintas organizaciones sociales orientadas a atender las necesidades de los sectores populares. 
relaciones adquieren sentido en tanto son analizadas a la luz de procesos macro-estructurales. Es justamente la tarea de un proceso investigativo captar los nexos de los condicionamientos recíprocos entre lo cotidiano y lo estructural (Achilli, 2005).

En virtud de esta propuesta me centré en el análisis de las relaciones entre lo dominante y lo subalterno antes que en su presentación como entidades autónomas y contrapuestas. Por este motivo, específicamente en relación al análisis de las experiencias educativas del Bachillerato Popular y del espacio del FinEs, me interesé por mostrar la presencia de elementos educativos propios del sistema educativo oficial en la cotidianeidad de estas experiencias educativas civiles, antes que en su distanciamiento o contraposición respecto de aquel ${ }^{6}$. En relación al análisis de los saberes cotidianos de la militancia territorial, el enfoque relacional orientó mi mirada hacia la forma en que la relación cotidiana de los militantes con distintos actores sociales (pobladores de la zona, pero también agentes y funcionarios gubernamentales) demanda y produce saberes específicos y en función de contextos políticos y sociales concretos.

Esos contextos, en tanto son entendidos como lógicas de conexión profunda de los cotidianos sociales con las tendencias hegemónicas (Achilli, 2015), configuran lo que los sujetos deben y pueden aprender en tanto límite y posibilidad) para desarrollar su práctica política. Entiendo que es en este sentido que Antonio Gramsci planteó que "toda relación de hegemonía es, necesariamente, una relación pedagógica" (Crehan 2009: 177). La relación entre sectores dominantes y subalternos -siempre variable y social e históricamente situada- se vuelve educativa o pedagógica en tanto ambos sectores deben apropiarse de los saberes cotidianos que le permitan incidir con mayor o menor grado de acierto en esa relación y a favor de sus propios intereses.

Es precisamente para enfatizar esta cuestión que decidí utilizar la categoría de saberes cotidianos propuesta por Ágnes Heller a propósito de su conceptualización sobre

6 Se trata de elementos educativos que son valorados para la práctica educativa cotidiana -aunque no existieran controles estatales sobre la forma en la cual se desarrollan estas experiencias- pero también reformulados y apropiados de diversas maneras por los sujetos. Dar cuenta de estos procesos me llevó a confluir con otros autores (como García 2016, 2017, López Fittipaldi 2015, 2019 o Santillán 2019) con quienes realizamos señalamientos críticos respecto de una tendencia mayoritaria de las investigaciones argentinas sobre experiencias educativas desarrolladas por movimientos y organizaciones sociales representada por trabajos como Gluz y Saforcada (2007), Ampudia y Elizalde (2008) o Michi (2008). El principal señalamiento que realizamos es que estos trabajos tienden a soslayar el análisis de las relaciones entre estas experiencias y las actuaciones, las políticas y las instituciones estatales, a las cuales identifican linealmente como aparatos de reproducción de la desigualdad social y presentan como contrapuestos y antagónicos a las experiencias educativas de los movimientos y organizaciones. De igual manera, estas últimas suelen ser presentadas de un modo reificado como alternativas pedagógicas distantes del sistema educativo oficial, contra-hegemónicas, horizontales o con matrices pedagógicas emancipatorias. la vida cotidiana y la cotidianeidad social. La autora entiende a los saberes cotidianos como "la suma de nuestros conocimientos sobre la realidad, que utilizamos de un modo efectivo en la vida cotidiana del modo más heterogéneo (como guía para las acciones, como temas de conversación, etcétera)" (Heller, 1977: 317). Los saberes cotidianos comprenden el saber qué y el saber cómo que se vuelven inevitables para poder existir y "movernos en nuestro ambiente" y que no pueden ser escindidos del contexto histórico y del estrato social al que pertenecen los sujetos (Heller, 1977; Lorenzatti, 2018).

En el mismo sentido, recupero la categoría de apropiación porque es utilizada -junto a la de experiencia formativa- en varios estudios antropológicos sobre saberes no escolares (Dacuña y Garcés 2010; Padawer 2010, 2013; Lorenzatti 2018; Montenegro 2019). Con esta noción se alude a la relación dialéctica entre las condiciones estructurales que ponen a disposición determinados bienes culturales (lenguajes, políticas, recursos, sentidos) y la capacidad individual y colectiva de los sujetos para hacer uso (para apropiarse) de esos bienes (Heller, 1977; Rockwell, 1996) Desde este lugar se complejiza el proceso de aprendizaje humano más allá del modelo de simple "interiorización" o "inculcación" para centrarse en la relación activa entre el sujeto particular y la multiplicidad de recursos y usos culturales disponibles objetivados en los ámbitos heterogéneos que caracterizan a la vida cotidiana (Padawer, 2010).

Retomé también para mi análisis sobre los saberes cotidianos de la militancia territorial los aportes de diversos trabajos antropológicos sobre tramas políticas colectivas, activismo y trayectorias de militancia, tales como Manzano, 2008; Borges, 2009; Quirós, 2009, 2011; Vázquez, 2011; Vommaro y Quirós, 2011. Estos trabajos me recordaron -en línea con el enfoque relacional- la importancia de analizar tanto la interacción cotidiana entre actores políticos colectivos y programas, políticas y agentes estatales como en el saber-hacer adquirido por los militantes y referentes de las organizaciones sociales a propósito de esa interacción. Si bien estas investigaciones no abordan estos procesos en clave educativa -sino más bien desde el punto de vista de la especialización técnica o de la formación de los sujetos- me permitieron comprender mejor en torno a qué eventos cotidianos se despliegan los conocimientos adquiridos por los y las militantes en sus rutinas políticas diarias.

Al mismo tiempo, al proponer este enfoque respecto de los saberes de la militancia tomo distancia de un conjunto de trabajos (por ejemplo, Sales Caldart 2000, Zibechi 2007 o Palumbo y Guelman 2019) que desde mi punto de vista realizan una homologación entre los postulados político-ideológicos de las organizaciones sociales y los saberes que en ellos circulan y son apropiados. Entiendo que esta operación se produce justamente porque se soslaya el análisis de los distintos contextos socio- 
históricos (y las relaciones de fuerza entre los grupos sociales fundamentales en cada uno de ellos) en tanto circunstancias que configuran límites y posibilidades para la circulación, producción y apropiación de determinados saberes cotidianos de la práctica política.

El análisis que despliego en los próximos apartados se fundamenta en materiales surgidos de un trabajo de campo que realicé entre los años 2009 y 2013. Este trabajo consistió centralmente en observaciones participantes de los recorridos habituales de los sujetos por asentamientos y barrios de la zona sud-este de la ciudad, de movilizaciones y cortes de calle en el centro de la misma y de esperas y reuniones con funcionarios en distintos ministerios públicos provinciales, entre otras acciones. También, a partir de entrevistas en profundidad, recuperé sus relatos acerca de los inicios de su militancia política, acerca de la fundación del Movimiento y sus sentidos acerca de algunos procesos del presente de la organización. En ese recorrido, el análisis se orientó por la preocupación señalada por Achilli (2015): no sólo atender a los cómo de los fenómenos culturales (tendencia mayoritaria en la antropología actual) sino también al por qué de los procesos, prácticas y relaciones que nos interesa estudiar.

\section{Los orígenes de la militancia territorial de Eugenia y Gastón}

Cuando inicié mi investigación a fines de la década del 2000 Eugenia y Gastón tenían cerca de 40 años cada uno y habían formado una familia con dos hijos. La pareja se había conocido a mediados de la década de 1990 a partir de una militancia juvenil compartida en el cristianismo de base. En el año 1999, ambos habían pasado a formar parte del Movimiento de Vecinos Autoconvocados de Córdoba [MVA]. Este era una organización vecinal que había surgido a propósito de las políticas neoliberales que se venían aplicando en el país y en el continente. Los objetivos centrales del MVA eran parar la ejecución de remates de viviendas, amparar a los desocupados cuyas cuentas bancarias eran embargadas o exigir la resolución de problemas de infraestructura urbana como el tendido de redes cloacales y de agua potable, entre otras problemáticas (Franco y Medina, 2011)

En el marco de un clima de gran efervescencia social la toma (la ocupación) de edificios públicos se fue volviendo la principal metodología de protesta del MVA. Entre otros, el Movimiento Vecinalista tomó por períodos variables de tiempo los espacios edilicios del consulado de España, los Tribunales Federales de Córdoba, el Ministerio de Trabajo provincial, el Ente Regulador de Servicios Públicos, la Defensoría del Pueblo o la Catedral de Córdoba. Del paso por el MVA, Eugenia y Gastón recuperaban distintas vivencias personales y políticas, pero entre ambos reconstruían un paisaje social atravesado tanto por una gran movilización social (que incluía enfrentamientos diarios con las fuerzas de seguridad) como por condiciones de vida sumamente precarias para la población:

“la gente no tenía trabajo, no podía pagar impuestos, no podía pagar servicios, y bueno, empezaba una deuda hasta que le llegaba la intimación del remate (...) [en la toma de la catedral] había unas 40, 50 personas fijas... [pero] circulaban 200 o 300 personas por día (...) se hacía una polla [una colecta] para hacer un guiso (...) entonces se compartía la comida en una mesa grande con un montón de vecinos y después de comer venían otros y rumiaban [comían los restos] de lo que había dejado la primera tanda... venía mucha gente que estaba muy mal"

(Eugenia, entrevista 25/06/2012)

"Cuando tomamos la catedral había presiones de la policía, había infiltrados... a la noche hacíamos guardias en el campanario... Y siempre había roces con la cana [la policía], te provocaban (...) tomamos la legislatura un día entero... Tribunales también (...) Ahí vino la policía y dijo que si en 15 minutos no se desalojaba iban a proceder...y como nos quedamos ahí hubo cuarentipico de presos durante dos días (...) era un época en que nos jugábamos todo...todos los días"

(Gastón, entrevista 25/06/2012)

Durante las tomas se solían realizar además escraches ${ }^{7}$ a funcionarios estatales. Entre los numerosos recortes de diario que la pareja guardaba de aquella época, hubo una que llamó particularmente mi atención. En ella podía verse a Eugenia gritando en la cara de un funcionario, rodeada de una gran cantidad de vecinos entre los que se encontraba Gastón. Respecto de esta fotografía, Eugenia me relató: "íbamos a escrachar a los funcionarios, los re puteábamos [insultábamos] (...) no era como ahora, que pedís una reunión, vas a negociar... no. Ahí entrábamos y entrábamos a las patadas y a las puteadas"

Con el crecimiento de los movimientos de trabajadores desocupados a mediados del año 2001 el MVA se hizo eco de las luchas "piqueteras" que se desarrollaban fundamentalmente en el Gran Buenos Aires. Comenzaron entonces a articularse acciones entre los movimientos vecinalistas y los de trabajadores de Desocupados y apoyarse mutuamente:

“Viajamos a ese corte gigante que hubo en La Matanza [partido del Gran Buenos Aires colindante con la ciudad capital]... Fuimos para dar el apoyo del MVA de Córdoba... Un tiempo después vino Martino ${ }^{8}$ a Córdoba

\footnotetext{
7 El término "escrache" alude en Argentina a una acción de denuncia pública de una persona en su domicilio, lugar de trabajo u otro espacio público y en función de su implicación o responsabilidad en determinado delito o defraudación. La palabra comenzó a ser utilizada en nuestro país a mediados de la década de 1990, cuando los organismos de derechos humanos "escrachaban" en sus domicilios a los genocidas de la última dictadura militar indultados de sus crímenes por el gobierno de Carlos Menem.

8 Roberto Martino era el dirigente nacional del Movimiento Teresa
} 
y como que se interesó por esa metodología nuestra de las tomas iviste?... '¿Cómo es esto de la tomas?' nos preguntaba... ahí le explicamos que no había que decirle toma porque te podían levantar cargos, había que llamarlo 'encuentro permanente de vecinos autoconvocados' (...) Y a la semana más o menos tomaron ellos el Ministerio de Trabajo de Buenos Aires"

(Gastón, entrevista 25/06/2012)

A la par de estas acciones la organización de vecinos comenzó a incluir en sus demandas -ya en el año 2002el pedido de planes sociales de empleo transitorio. Particularmente, se demandaban los recién lanzados planes "Jefes y Jefas de Hogar Desocupados" que exigían, a cambio de una suma de 50 dólares mensuales, una "contraprestación" de 4 horas diarias de trabajo en proyectos productivos o en actividades de capacitación. Cuando el MVA accedió finalmente a estos planes Eugenia y Gastón se inscribieron como beneficiarios del mismo realizando la contraprestación correspondiente en una escuela de oficios para jóvenes creada por el MVA y ubicada en la zona oeste de la ciudad. Eugenia realizaba allí tareas de apoyo escolar y Gastón, por su parte, realizaba el mantenimiento de las instalaciones.

Unos años después -por motivos en los que no puedo detenerme aquí- el MVA se desarticuló y, en un breve lapso posterior, Eugenia y Gastón se unieron a otros jóvenes y fundaron el Movimiento. Según cada uno de ellos me relataba, la nueva organización se fundó fuertemente asociada al componente social, las demandas y la metodología de lucha de las organizaciones de desocupados al que se habían acercado a partir de su militancia vecinalista. Por este motivo, las primeras acciones del Movimiento se orientaron a "hacer pie" en las villas de emergencia de la zona sud-este, próxima al lugar donde vivían Eugenia y Gastón. Persiguiendo ese objetivo, comenzaron a realizar ollas populares (comidas comunitarias) en la casa de algunos habitantes de la zona. En torno a esas "ollas" Eugenia, Gastón y otros jóvenes activistas del Movimiento se reunían para cocinar, comer y conversar con los habitantes. El tiempo diario pasado allí comenzó a volverse cada vez más extenso, incluyendo actividades diversas como limpiar un terreno de escombros, acompañar a una vecina al centro médico del barrio para efectuar un reclamo o simplemente tomar mates y conversar.

El tipo de militancia que comenzaron a desarrollar Eugenia y Gastón en los inicios del Movimiento se emparenta con el planteo efectuado por Vázquez (2011) a propósito de su investigación sobre generaciones militantes en movimientos de desocupados/territoriales. Según sostiene la autora, hacia finales de la década de 1990 y principios de la 2000 existió en nuestro país una importante camada

Rodríguez, organización "piquetera" de trabajadores desocupados de alcance nacional. Puede encontrarse en Quirós (2011) una etnografía que incluye referencias sobre su figura y sobre la toma del Ministerio de Trabajo mencionada más adelante en este extracto de entrevista. de activistas que, proviniendo de sectores medios, se integraron a los movimientos de desocupados a través de una militancia poli-rubro (que implicaba realizar actividades diversas, orientadas a demandar soluciones para diversas problemáticas de la vida cotidiana de los sectores populares) y de tiempo completo (conviviendo o viviendo muy cerca de los habitantes de villas y barrios pobres de las grandes urbes). Ese tipo de involucramiento político los llevaba a abandonar o al menos suspender el desarrollo académico o laboral personal, lo que la autora califica como un "desclasamiento" realizado en vistas a una mimetización con los sectores populares con los cuales estos activistas construían las organizaciones de desocupados ${ }^{9}$.

Este proceso también podía apreciarse en las trayectorias de Gastón y Eugenia. Ella, que poseía título de maestra de grado, no había ejercido como tal desde el inicio de su paso por el MVA y también en los primeros años de creación del Movimiento. Gastón, por su parte, pertenecía a una familia con varios miembros empleados en la Empresa Provincial de la Energía quienes le ofrecían facilidades para ingresar a trabajar en este ente público. No obstante, según ellos mismos referían, habían optado por sobrevivir con el magro ingreso de los planes más algún eventual empleo informal. Aunque se tratara de austeras condiciones de vida, éstas les permitían disponer de una jornada casi completa para entregarse a la actividad militante en las villas de la zona.

Fue en este contexto que a lo largo de la década de 2000 el Movimiento creció y consolidó su presencia en el sector sud-este de la ciudad: en alrededor de 7 barrios o villas distintas había vecinos y vecinas que concurrían a participar de los cortes y las movilizaciones organizadas por el Movimiento o que participaban de alguno de los emprendimientos productivos (en comedores populares, fabricación de ladrillos o emprendimientos textiles, entre otros) sostenidos a partir de la gestión de planes de trabajo cooperativo. Sin embargo, la consolidación del Movimiento como una organización de desocupados/ piquetera se vio atravesada por diversos procesos sociales que a medida que avanzaba la década del 2000 comenzaron a transformar el horizonte de existencia de estos movimientos sociales. Esos procesos configurarían en parte los saberes cotidianos que serían apropiados por Eugenia y de Gastón en el marco de su militancia territorial.

\section{Los saberes cotidianos de Eugenia y Gastón a propósito de la militancia territorial}

A partir del año 2003, con el inicio del gobierno de Néstor Kirchner (primer gobierno elegido mediante elecciones con posterioridad a la crisis político-institucional del año

\footnotetext{
9 Es importante señalar que este proceso de "desclasamiento" de los y las militantes no es en nuestro país exclusivo de este momento histórico sino que puede rastrearse -fundamentalmente- en las experiencias de militancia "basista" de las décadas de 1960 y 1970 y vinculadas tanto al peronismo como a la Teología de la Liberación.
} 
2001) comenzó a desarrollarse una fase de incremento de la actividad económica cercana al $8 \%$ anual que incidió de manera positiva en las tasas de empleo a nivel nacional (Schneider, 2013). A la par de esta recuperación económica, comenzaron a ponerse en práctica una serie de estrategias gubernamentales tendientes a desarticular (o bien a articular para el partido político en ejercicio del poder) los colectivos sociales que habían protagonizado los eventos de protesta más masivos entre los años 1999 y 2002. Me refiero a medidas como la integración de dirigentes y militantes de estas organizaciones en instancias políticas institucionales; el recorte y re-direccionamiento selectivo del gasto social hacia organizaciones cercanas al gobierno; o la erosión de las estrategias de confrontación por medio de la criminalización y judicialización de los actos de protesta (Svampa, 2004; Fornillo et al., 2008).

A su vez, estas estrategias confluyeron con transformaciones en materia de política social que condujeron a una reconfiguración de los planes sociales existentes tales como la baja del Plan Jefes y Jefas de Hogar, la implementación de planes diversos y menos masivos (como el Argentina Trabaja lanzado en el año 2008) o la implementación de políticas como la Asignación Universal por Hijo. Esta reconfiguración, que supuso en algunos casos un acceso más universal y democrático a ciertos beneficios sociales, impactó en los recursos que cotidianamente demandaban y gestionaban las organizaciones sociales: tanto porque las nuevas políticas pasaron a ser gestionadas entre beneficiarios y estado sin intermediación de las organizaciones sociales (Retamozo, 2011) como por un manejo de los planes cooperativos que tendió a beneficiar a las organizaciones y los gobiernos provinciales alineados al gobierno nacional (Sleiman, Morua y Audisio, 2015).

En este contexto, la confluencia entre actuaciones estatales orientadas a la desmovilización, las tasas favorables de recuperación económica y la transformación en las políticas sociales tendieron a debilitar las consignas y la capacidad de movilización y presión colectiva de las organizaciones "piqueteras" o de trabajadores desocupados. Como plantean Svampa (2004) y Masetti (2011) esto produjo que al interior de las mismas se fuera desplazando el centro de la acción de la confrontación pública (movilizaciones, piquetes y tomas) hacia el desarrollo de actividades centradas en la atención del sostenimiento de proyectos productivos (cooperativas textiles, bloqueras, comedores y merenderos populares entre otros), en el reclamo periódico de recursos (bolsones de alimentos, útiles escolares, materiales de construcción) y en la demanda de los nuevos pero menos masivos planes sociales. En ese desplazamiento, a su vez, los movimientos "piqueteros" o de desocupados pasaron paulatinamente a identificarse exclusivamente como organizaciones territoriales.
Si bien las demandas de recursos y de los nuevos planes se producían en este nuevo contexto político también a través de movilizaciones y cortes de calle (aunque de menor envergadura y duración) se combinaban al mismo tiempo con una serie de tareas que los militantes denominaban como tareas de gestión. La observación detenida de las prácticas militantes implicadas tanto en las movilizaciones y cortes de calle como en las tareas de gestión me permitió reconstruir algunos de los saberes cotidianos apropiados por Gastón y Eugenia en el marco de este momento específico que atravesaban las organizaciones territoriales en general y el Movimiento en particular. Recuperaré aquí la descripción detallada de una de estas demandas (el reclamo que cada año realizaba el Movimiento junto a otras organizaciones territoriales para obtener útiles escolares) porque aunque la misma presentaba particularidades, en ella se condensaban saberes cotidianos similares a los movilizados por Gastón y Eugenia a propósito de la demanda de otros recursos y en relación con diversas dependencias gubernamentales.

"La acción por los útiles" comenzaba a ser preparada a inicios del mes de febrero, unas semanas antes del inicio del ciclo lectivo escolar. En primer lugar, se organizaba una movilización al Ministerio de Educación provincial, para lo cual Eugenia y Gastón visitaban previamente todos los barrios en los que el Movimiento "tenía presencia". El horario y día de esa visita era pautada previamente por teléfono con cada una de las referentes territoriales del Movimiento (todas ellas mujeres), delegando en ellas la tarea de reunir para ese entonces a las personas que fueran a formar parte de la movilización (madres y padres cuyos hijos e hijas serían potenciales receptores de estos recursos).

Al tomar parte en algunas de esas reuniones entre Eugenia, Gastón, las demás referentes territoriales y las personas que participarían de la jornada pude observar cómo la pareja detallaba en esas instancias las cuestiones operativas relativas al evento que se estaba por realizar. Pero además, dedicaban una parte importante de sus alocuciones a explicar la justeza del reclamo, a denunciar las condiciones de vida de los sectores populares y a enfatizar en la importancia de la participación ("ser muchos para presionar más", decía Gastón) en la acción que estaba por llevarse a cabo.

Unos días después de esta primera invitación se debía volver a relevar cuántas personas se estimaba que participarían del reclamo y comenzar a realizar los listados de los niños y niñas para los cuales se iban a pedir "los útiles". En estas listas se debían incluir datos como: nombre, edad, grado, escuela y nombre de los padres. Como se pedían también zapatillas y guardapolvos se debía detallar el número de calzado y el talle de vestimenta de cada niño. Dado que los datos a recabar eran muchos, Eugenia y Gastón debían pasar largo tiempo recopilando esta información en planillas junto a las referentes de cada 
barrio. Luego guardaban cuidadosamente estos papeles en una carpeta con la que asistían el día del reclamo frente al Ministerio de Educación Provincial.

Los tres o cuatro días previos a la movilización se ponían a punto las banderas, banderines, pecheras, redoblantes, megáfonos y todo aquel otro material que fuera a ser utilizado. Estas tareas solían quedar a cargo de Gastón, quien las realizaba en general con las mujeres que participaban de la cooperativa textil que funcionaba en el local del Movimiento. Además, el hombre pasaba gran parte de su tiempo coordinando (a través de llamadas telefónicas o reuniones presenciales) qué recursos aportaría cada una de las organizaciones que formarían parte de la jornada, dado que la acción por los útiles solía ser realizada en conjunto con otras organizaciones territoriales. Esto se volvía especialmente importante si se iba a realizar, por ejemplo, una comida compartida por todas las organizaciones mientras se sostenía el corte de calle frente al Ministerio. Debía planificarse además cómo se efectuaría el traslado de estos materiales desde los barrios hasta el centro de la ciudad, lo cual solía realizarse o bien en taxi o con un camión alquilado (dado que el Movimiento no disponía de vehículo propio).

Por último, debía definirse un punto de encuentro en la zona de confluencia de todos los barrios de los que provendrían participantes de la movilización. Una vez allí reunidos, Gastón repartía a las referentes territoriales el dinero necesario para pagar el pasaje de colectivo de ida y de vuelta de los participantes de cada barrio. Eugenia, mientras tanto, confeccionaba -junto a las otras referentes territoriales- listados de asistencia de quienes estaban efectivamente allí. Cuando se llegaba finalmente a la puerta del Ministerio se esperaba que arribaran el resto de las organizaciones $y$, una vez todos reunidos, se cortaba totalmente la calle para la circulación de vehículos.

Luego de iniciado el corte, los representantes de cada organización ingresaban al edificio y pedían formalmente ser atendidos por un funcionario ministerial. Sin embargo, no pedían por cualquier funcionario si no por alguno específico: la experiencia previa les había enseñado a distinguir entre los funcionarios de distinto rango, la potencial capacidad de respuesta de cada uno de ellos y la importancia de reunirse con aquel con el cual habían forjado previamente una relación interpersonal de conocimiento mutuo. Cuando la reunión con el/los funcionario/s finalizaba, los militantes salían afuera a contar a los demás asistentes lo que se había acordado, enfatizando en la importancia de haber presionado "desde afuera" con el corte de calle.

Lejos de ser este el final del reclamo, era sólo el inicio o la apertura de la demanda. Lo que restaba era un largo y tedioso proceso que podía durar desde el mes de febrero hasta fines del mes abril. A lo largo de ese proceso, Eugenia y Gastón se veían implicados en una extensa serie de llamados telefónicos, envío de mensajes de texto por celular y nuevas "idas" al Ministerio de Educación para coordinar las entregas y reclamar por las cantidades y calidades de lo entregado. Además, cuando finalmente alguna de las partidas de los objetos reclamados llegaba al local del Movimiento, debía ser almacenada hasta que arribara otra de las partidas pedidas. Debía ser cuidadosamente mesurado el momento en que se comenzaba a repartir, teniendo en cuenta como variables tanto que alcanzara al menos para darles una parte significativa de lo demandado a cada barrio (para que ninguno se sintiera postergado en el reparto) como que la entrega no se produjera mucho después de iniciado el ciclo escolar.

Al mismo tiempo, cuando se realizaban las entregas había que cotejar que todos aquellos adultos que venían a buscar los útiles, guardapolvos y zapatillas hubieran asistido efectivamente a la movilización. Para esto se contaba con listas de asistencia confeccionadas por Eugenia. No obstante, podían realizarse excepciones, pero éstas debían estar fundadas en una serie de consideraciones que iban desde la conducta generalizada de esa persona para con el Movimiento (si era una persona confiable, que asistía con regularidad a las movilizaciones, que se mostraba solidario con los demás) hasta el grado de necesidad material que acusara tener (cantidad de hijos, enfermedades, tipo de vivienda que poseía). Esas consideraciones sólo podían sustentarse en una estrecha familiaridad y un gran conocimiento de los militantes respecto de las personas que participaban de las acciones: la legitimidad de aquellos emanaba de la justeza de sus excepciones y ésta del saber cotidiano que se poseía sobre las condiciones de vida de los pobladores de las villas y barrios en función de una cotidianeidad compartida.

Esto es señalado también por otros trabajos antropológicos (como Borges 2009, Quirós 2009, 2011, Quirós y Vommaro 2011) que -aunque no lo hacen en clave de apropiación de saberes o conocimientos- proponen que es la cotidianeidad compartida la que permite la existencia de un grado de inter-conocimiento mutuo necesario para realizar una excepción considerada como justa por quienes participan de las acciones de los movimientos. Un escaso conocimiento de una situación de carencia extrema o, peor aún, la credulidad ante quien acusa una necesidad que no tiene, podían desnudar una ignorancia por parte de los militantes (una falta de saber cotidiano) que debilitaba su legitimidad como referentes de la organización.

Además de señalar un tipo de involucramiento político específico (que definí anteriormente como poli-rubro y de tiempo completo, retomando a Vázquez, 2011) estos saberes indican cómo se tramaba la construcción 
política del Movimiento con formas específicas de actuación estatal. Los programas de trabajo cooperativo (ciertamente escasos en ese momento para provincias opositoras al gobierno nacional), los modos de entrega de recursos y los canales de diálogo permitidos por los funcionarios modelaban la actividad cotidiana de los militantes y su organización. Al mismo tiempo, y tal como señala Manzano (2008), estas formas de especialización técnica redundan en la posibilidad de apropiación de conocimientos que permiten el acceso a recursos, a cierto control colectivo sobre las actuaciones estatales y que configuran -o configuraban al menos durante este período- las actividades en torno a las cuales el Movimiento se construía cotidianamente.

Como vimos, el proceso desarrollado a propósito de la demanda de útiles escolares implicaba una serie de acciones que se apoyaban en todo un conjunto de saberes cotidianos específicos: saber planificar reuniones en cada barrio; saber persuadir en esas reuniones a los vecinos -padres y madres- de la necesidad de asistir masivamente a la movilización; saber confeccionar planillas de datos personales y escolares de cada niño y niña; saber organizar la movilización (armar, mantener y desplazar los materiales necesarios para la jornada así como administrar los recursos económicos para el transporte y alimentación de las personas durante la jornada); saber identificar funcionarios con los cuales obtener reuniones exitosas para el proceso de demanda; saber reiterar periódicamente a los funcionarios (o a sus secretarias y secretarios) por teléfono o personalmente el reclamo por los recursos demandados; saber repartir con justeza los recursos que se van obteniendo (en qué momento, a quiénes, realizando qué excepciones); por último, saber reclamar nuevamente a las autoridades por las cantidades y las calidades de lo entregado.

Todo este conjunto de saberes cotidianos implicados en el desarrollo de la militancia territorial de Gastón y Eugenia y que iban desde la movilización y piquete callejero hasta los más tediosos procesos de seguimiento de la entrega de una partida de recursos se desarrollaba en el marco de unas condiciones sociales y políticas específicas. La naturaleza aprendida de esos saberes (y por lo tanto situada social e históricamente) se ponía de manifiesto cuando los militantes relataban cómo se habían iniciado en las relaciones de negociación (de "gestión") con el Ministerio de Educación provincial:

“nosotros al principio estábamos nada más con lo de la olla popular... pero desde otros movimientos de Buenos Aires con más experiencia nos empezaron a decir: '¿no tienen una gestión abierta en un Ministerio?' Nosotros en ese momento nos mirábamos y pensábamos '¿una gestión abierta?'¡Nos parecía una cosa que no la íbamos a poder lograr! Porque no teníamos idea cómo era ir a un ministerio a abrir gestiones"

(Eugenia, entrevista 5/08/2011)
No olvidemos que en el apartado anterior describí una fotografía del año 2000 en la cual la pareja aparecía increpando de manera frontal a un funcionario público adentro de su propia oficina en un Ministerio. Que diez años después Eugenia contara que se habían inquietado frente a la tarea de "abrir una gestión" -la cual, al menos a mis ojos, parecía ser mucho menos inquietante que el escrache a un funcionario en su propia oficinaexponía una transformación. Aquella por la cual los saberes cotidianos apropiados por los militantes para vincularse con (y demandar ante) los agentes y ámbitos estatales a finales de la década anterior -"a las patadas y las puteadas"- habían dejado de ser a mediados de la del 2000 saberes cotidianos viables para el desarrollo de las prácticas de militancia.

\section{Las actividades educativas tensionan los saberes cotidianos de las actividades territoriales}

Durante los últimos años de la década del 2000 comenzaron a realizarse en el seno del Movimiento algunas actividades educativas con niños y jóvenes de la zona, tales como espacios de apoyo escolar o talleres artísticos. Estas tareas eran llevadas a cabo por jóvenes activistas que comenzaron a acercarse al Movimiento pero que no eran personas que vivieran en la zona ni en sus cercanías, sino más bien en el centro o macrocentro de la ciudad. Casi todos ellos eran, además, estudiantes o graduados de instituciones universitarias o terciarias que combinaban su interés por desarrollar actividades políticas "barriales" con sus obligaciones estudiantiles y laborales.

Cuando a principios de la década de 2010 estas incipientes actividades educativas cristalizaron en el seno del Movimiento en experiencias de mayor envergadura (como el Bachillerato Popular y el espacio de FinEs primaria) se acrecentó rápidamente el número de activistas que se acercaban para participar como educadores. De hecho, por momentos estas personas llegaron a superar numéricamente a quienes se inscribían como estudiantes de estas experiencias educativas. Muchos de los nuevos activistas eran además militantes de agrupaciones estudiantiles, por lo que su participación en las experiencias educativas suponía un desafío de articulación entre el Movimiento y otros colectivos políticos provenientes de otros ámbitos sociales.

Este proceso de articulación con organizaciones políticas de otros ámbitos (particularmente las estudiantiles) y con activistas de orígenes sociales diferenciados es reseñado también por Vázquez (2011) a propósito de su análisis sobre generaciones militantes en organizaciones de desocupados (devenidas territoriales) en el sur del Gran Buenos Aires. Lo que propone la autora es que en ese encuentro pueden registrarse perfiles diferenciados de involucramiento político: quienes participan como educadores en las actividades educativas (a quienes la autora denomina como activistas educativos o culturales) 
desarrollan una militancia de tipo especializado (orientada casi exclusivamente a las actividades educativas y en función recorridos y credenciales académicas) y de medio tiempo (en tanto se realizaba a partir de una presencia puntual para dictar clases o para una reunión o asamblea vinculadas a los espacios educativos). En ese sentido, se trata de una lógica de militancia que difería de la de la militancia territorial y que para el caso de Gastón y Eugenia definí -recuperando también las categorías propuestas por Vázquez (2011) para los referentes territoriales- como multirubro y de tiempo completo.

Pero en el marco del Movimiento, la aparición de actividades educativas y la confluencia de activismos diferenciados no sólo implicó este encuentro de tipos de militancia diferenciados si no que significó también ciertas transformaciones en la propia práctica militante de Gastón y Eugenia ya que ambos se involucraron también como educadores de las actividades educativas. Gastón lo hizo como educador en el Bachillerato Popular -poniendo en juego los saberes que poseía por un paso breve y trunco por algunas carreras universitarias- aunque combinando su tarea con la atención y la coordinación de las tareas que se desprendían de las actividades territoriales. Eugenia, en cambio, comenzó a abocarse cada vez más a las tareas educativas, fundamentalmente en virtud de que, como ya he mencionado, poseía título de maestra. Además, había vuelto a ejercer paulatinamente su profesión en la segunda mitad de la década de 2000. Poco a poco comenzó a involucrarse cada vez más en las actividades educativas del Movimiento y desde un rol tácito de coordinadora general de las mismas.

Esta doble adscripción de ambos militantes en las actividades educativas y en las territoriales se veía reflejada además en un uso heterogéneo de nominarse a sí mismos y ser nominados por los demás. Mientras el resto de las referentes y de las personas que participaban de las actividades territoriales del Movimiento aludían a ellos como referentes territoriales, esta categoría no era utilizada en el marco de las actividades educativas. En ellas, el término usual con el cual se nombraban y eran nombrados, era el de militantes de la organización.

Al mismo tiempo, la dualidad de tareas y de tipos de involucramiento diferenciales en cada una de ellas comenzó a desatar algunas tensiones que fui registrando y que impactaron de manera particular en las trayectorias militantes de Eugenia y de Gastón. En el caso de Eugenia, comenzó a referir que se sentía "desbordada" de tareas y responsabilidades en virtud de su participación tanto en las actividades educativas -participación que tenía lugar fundamentalmente durante la semana y en paralelo con su trabajo formal- y en las actividades territoriales -a las que se abocaba fundamentalmente los fines de semana. En una conversación, Eugenia me refería que una de las causas de su desborde era el reclamo que le efectuaba una mujer que asistía a las clases del FinEs
Primaria -espacio en el que Eugenia dictaba las clases de matemática- y que además participaba desde hacía mucho tiempo en las actividades del sector territorial del Movimiento. Era, por lo tanto, una mujer que conocía a Eugenia en su rol de referente territorial.

Específicamente, esta mujer le había reclamado -bajo amenaza de dejar de asistir a clases- que le consiguiera los manuales del plan FinEs que el Ministerio de Educación de la provincia recibía del Ministerio de Educación nacional y que, por intermedio de Eugenia (encargada, según sus propoias palabras, de gestionar estos recursos) llegaban a manos de las mujeres que eran estudiantes del espacio. Sin embargo, sucedía que esta mujer -como otras- se había incorporado tardíamente al ciclo lectivo, cuando Eugenia ya había realizado su visita anual para gestionar los manuales. Además, como había varios de estos libros por área curricular del Plan, solía ocurrir que en una sola ida al Ministerio no siempre se obtenía el "combo" completo de manuales que precisaba cada nueva estudiante, por lo que Eugenia debía reitera el reclamo y las visitas periódicas ante el ente oficial.

Hablando acerca de la angustia que le había provocado el reclamo de esta mujer/alumna, Eugenia relataba:

"¡Lo que ella no entiende es que es re burocrático todo! Es ir otra vez al Ministerio a hablar con el Secretario y [simula diálogo] '¿tenés los manuales?', 'no los tengo todavía a los manuales'... Y es cierto que no los tiene! Me los va a pichulear [regatear] a mí porque a la vez se lo pichulearon a él desde [el Ministerio de la] Nación... Yo ya les pedí a las mujeres que me tengan paciencia, les dije a todas que sean solidarias, que se presten los Manuales entre ellas, que sientan que son parte de un colectivo"

(Eugenia, Registro de Campo, 06/11/2010)

Estas palabras de Eugenia expresan, a mi entender, las tensiones que desataba la confluencia entre distintos tipos de involucramiento militante y los saberes cotidianos asociados a los mismos. Como vimos en el apartado anterior, en el marco de las actividades territoriales y de los saberes cotidianos asociados a ellas, merece quien hace: los vecinos y vecinas merecen bolsones de mercadería o de útiles cuando marchan, cuando están bajo el sol del piquete o cuando asisten a las actividades de la organización. Como contrapartida, los militantes y referentes merecen paciencia y confianza por parte de los vecinos y vecinas en función de la energía invertida en gestionar bolsones, recursos o manuales de texto. Por este motivo, en el universo de la militancia territorial, culpabilizar al gobierno/al Estado porque nada se consigue no puede ser más que un argumento excepcional para justificar ante quienes se han movilizado el fracaso del reclamo: es por esto que resultaba habitual registrar (como también releva Quirós, 2009) la asociación entre obtención de recursos y capacidad de gestionar de los militantes antes que entre la primera y las actuaciones/ 


\section{políticas estatales.}

En este sentido, interpreto el malestar de Eugenia como una expresión de las tensiones desatadas entre las actividades educativas y las territoriales, tensión que redundaba en el debilitamiento de los saberes cotidianos apropiados anteriormente en función de su militancia territorial. Al dejar de demostrar su saber en torno a las actividades territoriales Eugenia perdía, a su vez, el derecho de reclamar -al menos en los términos de la militancia territorial- paciencia y tolerancia por parte las mujeres. En este sentido, la convergencia entre ambos grupos de actividades y los saberes asociados a ellos era para la militante un punto de inflexión y de inicio en un tipo de involucramiento político que traería aparejado una nueva serie de saberes cotidianos.

En el caso de Eugenia, comenzó a referir que se sentía "desbordada" de tareas y responsabilidades en virtud de su participación tanto en las actividades educativas - participación que tenía lugar fundamentalmente durante la semana y en paralelo con su trabajo formaly en las actividades territoriales - a las que se abocaba fundamentalmente los fines de semana. En una conversación, Eugenia me refería que una de las causas de su desborde era el reclamo que le efectuaba una mujer que asistía a las clases del FinEs Primaria -espacio en el que Eugenia dictaba las clases de matemática- y que además participaba desde hacía mucho tiempo en las actividades del sector territorial del Movimiento. Era, por lo tanto, una mujer que conocía a Eugenia en su rol de referente territorial.

Específicamente, esta mujer le había reclamado -bajo amenaza de dejar de asistir a clases- que le consiguiera los manuales del plan FinEs que el Ministerio de Educación de la provincia recibía del Ministerio de Educación nacional y que, por intermedio de Eugenia (encargada, según sus propoias palabras, de gestionar estos recursos) llegaban a manos de las mujeres que eran estudiantes del espacio. Sin embargo, sucedía que esta mujer -como otras- se había incorporado tardíamente al ciclo lectivo, cuando Eugenia ya había realizado su visita anual para gestionar los manuales. Además, como había varios de estos libros por área curricular del Plan, solía ocurrir que en una sola ida al Ministerio no siempre se obtenía el "combo" completo de manuales que precisaba cada nueva estudiante, por lo que Eugenia debía reitera el reclamo y las visitas periódicas ante el ente oficial.

En el caso de Gastón, y al menos hasta el momento en el que se desarrolló mi trabajo de campo, su vinculación con las actividades educativas desató una serie de tensiones que no redundaron en la apropiación de nuevos saberes cotidianos. Por el contrario, su vinculación circunstancial con las actividades educativas reforzó su distancia respecto de los modos de involucramiento político que estas suponían: tanto durante su participación como educador del Bachillerato como posteriormente a la misma sostuvo siempre críticas de mayor o menor tenor respecto del modo de implicación que los activistas educativos sostenían con "el barrio" y los habitantes de la zona.

Para él, se trataba de un involucramiento insuficiente, que reforzaba la distancia social existente entre educadores y educados y que mostraba a los primeros como "agentes externos" frente a los ojos de los vecinos y vecinas del lugar. Es decir, como portadores de unos saberes vinculados a una trayectoria formativa o laboral cualitativamente distinta a la de los sectores populares. Y eso podía poner en riesgo aquello que para él era el verdadero espíritu de la militancia tal como la concebía: la construcción territorial con los habitantes de las villas y barrios de la zona a partir de un involucramiento poli-rubro y de tiempo completo, y de unos saberes cotidianos que expresaran una cotidianeidad compartida y unas condiciones de vida similares. En función del registro de sus malestares, no me sorprendió que luego de su "pasaje" por las actividades educativas definiera no volver a ellas y se concentrara exclusivamente en las actividades del sector territorial. Mientras que Eugenia comenzó a desarrollar un nuevo modo de involucramiento político que ponía en juego nuevos saberes cotidianos y debilitaba los saberes vinculados a las actividades territoriales, Gastón pasó por las actividades educativas y salió de ellas para reforzar el tipo de involucramiento y los saberes que ya poseía.

Que estas trayectorias diferenciadas se produjeran al mismo tiempo, en el marco de una misma organización y en relación a un mismo contexto socio-político se debe, a mi entender, al inicio de un proceso que tensionaba profundamente la identidad política fundacional del Movimiento: una identidad vinculada a los saberes cotidianos involucrados en una militancia de tiempo completo, que abarca una serie múltiple de actividades y que persigue la mimetización de los activistas con las condiciones de vida de los sectores populares. Esa identidad y esos saberes, forjados en otro contexto socio-histórico, pasaban ahora a convivir con otros modos de militancia y otros saberes cotidianos configurados por una nueva situación social. Aunque el análisis del devenir de esa tensión escapa a los objetivos de este artículo, pero al menos se ha esbozado aquí la génesis de la misma para futuros abordajes.

\section{Reflexiones finales}

Como relaté en la Introducción de este artículo, la investigación iniciada en el año 2009 estuvo orientada en primer lugar a indagar experiencias educativas impulsadas por el Movimiento, tales como el Bachillerato Popular o el espacio FinEs primaria. En el recorrido de ese análisis decidí también abocarme a la indagación de las actividades territoriales de la organización, planteándome interrogantes sobre la dimensión educativa que las mismas 
suponían. Esa indagación me llevó a reconstruir parte de la trayectoria militante de Eugenia y Gastón, así como a atender a las rutinas militantes cotidianas asociadas a las actividades territoriales y a reparar en las tensiones que despertaban esos saberes en relación con aquellos puestos en juego a propósito de las actividades educativas.

Al analizar estos procesos, considero que pude sostener una mirada amplia en torno a los procesos educativos en tanto se reconoce que al interior de las organizaciones y movimientos sociales estos procesos no sólo se limitan a las actividades o contextos que los sujetos reconocen como educativos -ya sean espacios formación política o a aquellos emprendimientos educativos como los que había impulsado el Movimiento. Al mismo tiempo, este análisis permite sostener un argumento que invita a debatir con las visiones que, si bien reconocen el aspecto formativo del involucramiento político y del desarrollo de prácticas de militancia, lo hacen homologando el proceso formativo a la adquisición de los principios ideológicos sobre los que se sustenta una organización. Fue buscando tomar distancia de estas visiones que no profundicé a lo largo de este texto en las caracterización política del Movimiento si no que centré mi esfuerzo en reparar en los contextos sociales que -en función de variables relaciones de poder entre sectores dominantes y subalternos- configuraron distintos límites y posibilidades a su accionar.

Por último, espero haber abonado con el análisis desplegado en estas páginas a una concepción que sitúe los procesos de apropiación de saberes cotidianos de la militancia en el marco del enfoque relacional en antropología. Considero que esto es posible en tanto y en cuanto entendemos que no existen -como entidades aisladas y contrapuestas- saberes dominantes producidos por los sectores dominantes y saberes subalternos producidos por los sectores subalternos y las organizaciones y movimientos que los representan. Lo que existe son saberes que producen en el marco de la relación -siempre variable, histórica, conflictiva y socialmente situada- entre ambos sectores. De las demandas masivas de planes sociales a las intrusiones belicosas en las oficinas de los funcionarios, de la apertura de "una gestión" en un Ministerio a la confluencia con nuevos actores sociales con otros tipos de involucramiento político, los sujetos aprenden cómo denunciar, cómo demandar y cómo hacer política. Desde ya, la apropiación de esos saberes no siempre es exitosa: incluye yerros, necesidades de recalcular, frustraciones y enojos, pero también pequeños o grandes logros más o menos significativos para la mejora de las condiciones de vida de las grandes mayorías.

\section{Referencias bibliográficas}

Achilli, E. (2005). Investigar en antropología social. Los desafíos de transmitir un oficio. Rosario: Laborde.

Achilli, E. (2015). Hacer antropología. Los desafíos del análisis a distintas escalas. Boletín de Antropología y Educación. Número Especial dedicado al III SeminarioTaller RIAE, 103-107.

Ampudia, M. y Elisalde, R. (2008) (Comps.) Movimientos sociales y educación. Teoría e historia de la Educación Popular en Argentina y América Latina. Buenos Libros: Buenos Aires.

Borges, A. (2009). O emprego na política e suas implicações teóricas para uma antropología da política. En M. Grimberg, M. I. Fernández Alvarez y M. Carvalho Rosa (Eds.) Estado y movimientos sociales: estudios etnográficos en Argentina y Brasil. pp. 179-203. Buenos Aires: Antropofagia.

Crehan, K. (2004). Gramsci, cultura y antropología. Barcelona: Bellaterra.

Dacuña, R. y Garcés, L. (2010) Identidades laborales y saberes del trabajo. Entre la teoría y el trabajo de campo. Cuadernos de Educación, 8, 139 - 151.

Menéndez, E. (2002). El malestar actual de la Antropología o de la casi imposibilidad de pensar lo ideológico. Revista de Antropología Social, 11, 39-87.

Menéndez, E. (2010). La parte negada de la cultura. Relativismo, diferencias y racismo. Prohistoria.

Montenegro, G. (2019). "El comedor como espacio formativo". Actas de las XI Jornadas Investigación Educativa, Pp. 409-419. Córdoba, 9, 10 y 11 de Octubre, FFyH-UNC.

Fornillo, B., García, A. y Vázquez, M. (2008). Perfiles de la Nueva Izquierda en la Argentina reciente. Acerca de las transformaciones de los movimientos de trabajadores de desocupados autónomos. Nómadas. Nómadas. Revista Crítica de Ciencias Sociales y jurídicas; 08, 219-239. DOI: http://pendientedemigracion.ucm.es/info/nomadas/19/ brunofornillo.pdf

Franco, M. J. y Medina, L. (2011). La protesta territorial en Córdoba entre el auge y la crisis neoliberal (1989-2003). En Actas de las VI Jornadas de Jóvenes investigadores. Buenos Aires, 10, 11 y 12 de Noviembre, Instituto de Investigación Gino Germani.

García, J. (2016). Bachilleratos Populares y Estado: relaciones complejas y dinámicas. PUBLICAR en Antropología y Ciencias Sociales, 21, 25-46.

García, J. (2017). No me importa si me aburro o me hacen hablar de política... necesito el título: la producción del 'sujeto crítico' en un Bachillerato Popular. Propuesta Educativa. 47 (1), 141-152. 
Gluz, N. y Safocarda, F. (2007). Autonomía Escolar: perspectivas y prácticas en la construcción de proyectos políticos. Educação: Teoria e Prática, 17(29), 11-32.

Guelman, A. y Palumbo, M. (2019). La construcción de pedagogías descolonizadoras: notas desde la praxis del trabajo en organizaciones sociales. Revista Colombiana de Educación, 76, 33-49.

Gordillo, M. (2011) Las temporalidades del 2001. ESTUDIOS, 26, 25-41.

Heller, A. (1977). Sociología de la vida cotidiana. Barcelona: Península.

Lorenzatti, Ma. del C. (2018). Conocimientos, prácticas sociales y usos escolares de cultura escrita de adultos de baja escolaridad. Pátzcuaro: CREFAL.

López Fittipaldi, M. (2015). Movimiento social y experiencia educativa. Estrategias para enfrentar el problema de la asistencia y el abandono escolar en un Bachillerato Popular de la ciudad de Rosario. Revista de la Escuela de Antropología, 21, 89-105.

López Fittipaldi, M. (2019). Movimientos sociales y educación. Experiencias de jóvenes en una escuela secundaria para adultos. Pilquen, 16(2), 29-42.

Manzano, V. (2008). Etnografía de la gestión colectiva de políticas estatales en organizaciones de desocupados de La Matanza-Gran Buenos Aires. Runa, 28, 77-92.

Masetti, A. (2011). Las tres transformaciones de la política pública asistencial. Entramados y perspectivas, 1 (1), 9-36.

Merino, G. (2012). El Movimiento Obrero Organizado, la crisis de 2001 y el gobierno de Duhalde. Socio-histórica, 30: $87-119$.

Michi, N. (2008). Movimientos campesinos y educación. Estudio sobre el Movimento dos Trabalhadores Rurais Sem Terra y Movimiento Campesino de Santiago del Estero- VC [tesis de doctorado no publicada, Universidad de Buenos Aires].

Padawer, A. (2010). Tiempo de estudiar, tiempo de trabajar: la conceptualización de la infancia y la participación de los niños en la vida productiva como experiencia formativa. Horizontes antropológicos, 34, 349-375.

Padawer, A. (2013). El conocimiento práctico en poblaciones rurales del sudoeste misionero: habilidades y explicitaciones. Astrolabio, 10, 156-187.

Quirós, J. (2009). Política e economia na ação coletiva: uma crítica etnográfica às premissas dicotômicas. Mana, 15 (1), 127-153.

Quirós, J. (2011). El porqué de los que van: Peronistas y piqueteros en el Gran Buenos Aires (una antropología de la política vivida). Buenos Aires: Antropofagia.

Retamozo, M. (2011). Movimientos sociales, política y hegemonía en Argentina. Polis 10 (28), 243-279.

Rockwell, E. (1996). Claves para la apropiación: Escolarización Rural en México. En Bradley Levinson; Douglas Foley y Dorothy Holland (Eds.) The Cultural production of educated person. Nueva York, EE. UU: State University of New York Press.

Sales Caldart, R. (2000). O MST e a formação dos sem terra: o movimento social como principio educativo. En La Ciudadanía Negada. Políticas de Exclusión en la Educación y el Trabajo. pp. 125-144. Buenos Aires: CLACSO.

Salvia, S. (2015). La caída de la Alianza. Neoliberalismo, conflicto social y crisis política en Argentina. Colombia Internacional, 84: 107,138.

Santillán, L. (2019). 'Nuestro norte son los niños'. Subjetividades políticas y colectivización del cuidado infantil en organizaciones sociales del Gran Buenos Aires. Runa, 40 (2), 57-73.

Sleiman, V., Morua, C. y Audisio, N. (2015) Humo, asfalto y conquistas. El Plan Argentina Trabaja y la lucha piquetera. El Aromo, 66. DOI: https://razonyrevolucion. org/humo-asfalto-y-conquistas-el-plan-argentina-trabaja/

Schneider, A. (2013). Política laboral y protesta obrera durante la presidencia de Néstor Kirchner (2003-2007). En Juan Grigera (Comp.), Argentina después de la convertibilidad (2002-2011). Pp: 97-115. Buenos Aires: Imago Mundi.

Svampa, M. (2005). "Las organizaciones piqueteras: actualización, balance y reflexiones" Disponible en http://www.maristellasvampa.net/archivos/ensayo22. pdfen. [Consultado el 04 julio 2018].

Vázquez, M. (2011). Socialización política y activismo: Carreras de militancia política de jóvenes referentes de un movimiento de trabajadores desocupados. Tesis de Doctorado en Ciencias Sociales, Facultad de Ciencias Sociales, Universidad de Buenos Aires. (inédita)

Vommaro, G. y Quirós, J. (2011). 'Usted vino por su propia decisión': repensar el clientelismo en clave etnográfica. Desacatos, 36, 65-84.

Zibechi, R. (2007). Autonomías y emancipaciones. América Latina en movimiento. Lima: UNMSM editora. 